\title{
Radiotherapy for the management of locally advanced squamous cell carcinoma of the head and neck
}

\author{
Christine Ko and Deborah Citrin \\ National Cancer Institute Radiation Oncology Branch Building 10, CRC, B2-3500 Bethesda MD \\ 20892
}

\begin{abstract}
Background-Squamous cell carcinomas of the head and neck (SCCHN) affect approximately 35,000 people in the United States yearly. Although survival has improved with advances in therapy, patients with advanced stages of SCCHN continue to have a poor prognosis. An understanding of rationale for treatment selection, newer developments in therapy, and treatment toxicity is critical.
\end{abstract}

Methods-Standard methods of treating locally advanced SCCHN are reviewed. Advances in medical and radiotherapeutic management are discussed and the toxicities of therapy are described.

Results-Post-operative chemoradiation is used in patients with high risk characteristics. Induction chemotherapy and altered fractionation radiation treatment have been evaluated as alternatives to definitive chemo-radiotherapy. Targeted agents such as cetuximab may prove to increase survival with minimal increase in toxicity profile. Technological improvements such as the use of intensity modulated radiation treatment (IMRT) have proven to decrease some debilitating side effects from radiation treatment.

Conclusions-Locally advanced SCCHN continues to present a therapeutic challenge. Survival, local control, and quality of life are all goals of treatment. The optimal method of treating locally advanced SCCHN is the subject of ongoing research. Long term side effects can be minimized with the use of newer technologies and with careful treatment planning.

\section{Keywords}

head and neck cancer; radiation treatment; chemotherapy

\section{Introduction}

Approximately 34,000 patients develop head and neck cancers each year in the United States and 7,550 of these patients will die of their disease (Jemal et al. 2007). In North America and Europe, tumors of the mucosal surfaces of the head and neck usually arise from the oral cavity, oropharynx or larynx, whereas in Mediterranean countries and in the Far East, nasopharyngeal cancer is more common (Titcomb 2001). The incidence of head and neck cancers is twice as high in men as it is in women, but rates have been declining in men since 1975 and in women since 1980. Known risk factors for squamous cell cancers of the head and neck (SCCHN) are tobacco use (cigarette, cigar or pipe smoking, smokeless tobacco), HPV infection, and excessive alcohol use.

Corresponding Author: Deborah Citrin, National Cancer Institute, Radiation Oncology Branch, Building 10, CRC, B2-3500, Bethesda MD 20892, (301)496-5457, Fax (301) 480-1064, Email: citrind@ mail.nih.gov. 
Early stage (Stage I and II) SCCHN accounts for 30-40\% of cases with expected long term disease free survival rates ranging from 60-90\%. Locally advanced SCCHN (Stage III and IV without metastases) accounts for the remainder of cases. Approximately $50 \%$ of patients with SCCHN present with locoregionally advanced disease that is potentially resectable and have a projected 5 year overall survival (OS) in the range of 40-50\%. Patients with unresectable locally advanced SCCHN have a distinctly poorer prognosis with a 5 year overall survival of approximately 10-40\% (Jemal et al. 2007; AJCC Staging Manual).

The therapy of SCCHN presents many challenges primarily because the head and neck region has many critical structures that can be damaged by tumor or treatment. These critical structures include the brain, brainstem, spinal cord, vertebral bodies, cranial nerves, carotid artery, pharynx, mandible, salivary glands, larynx, and muscles of the pharynx critical to swallowing. Damage to these tissues by tumor or therapy can result in significant structural, cosmetic, and functional deficits that negatively impact quality of life. Local recurrences and local progression of SCCHN are often incurable and eventually fatal. Because of the implications of local failure, the objective of many studies has been to improve locoregional control. Major secondary goals for patients receiving therapy for SCCHN are preservation of organ function, minimizing toxicity of therapy, maximizing cosmesis, and minimizing the impacts of therapy on quality of life.

Many early stage head and neck cancers can be treated with single local modalities such as surgical resection or radiation therapy (RT). In contrast, local and distant failure rates are unacceptably high in patients with locally advanced disease treated with a single modality (Vokes et al. 1993; Adelstein et al. 1996; Soo et al. 2005). Recent efforts have incorporated multimodality treatment regimens in which surgery, radiation, and chemotherapy are combined in the hopes of improving disease control.

Although patients with locally advanced head and neck cancers have benefited from multimodality treatment regimens with improved local control and survival rates, the cost has been a significant increase in toxicity (Cooper et al. 1995; El-Sayed and Nelson 1996; Pignon et al. 2000). In attempts to improve the therapeutic ratio, advances in surgical techniques, imaging (PET, MRI, CT), radiation (treatment planning, delivery technology), and chemotherapy have been implemented. An understanding of the rationale for embarking on multimodality therapy and an understanding of both the acute and late toxicities of these therapies is important for clinicians involved in the ongoing care and management of these patients. Finally, methods to assist in reducing and managing the expected toxicity of therapy are described.

\section{Treatment modalities}

\section{Post-operative radiation treatment}

Surgical therapy was long the primary treatment modality for patients with SCCHN. The high rates of local and regional failure in high risk patients lead to the use of radiotherapy as an adjuvant. Post-operative RT has been considered the standard of care for a subset of patients for many decades. It is often recommended for major risk features identified pathologically in the resection specimen such as positive margins or extracapsular extension in lymph nodes and for minor risk features, including multiple positive lymph nodes or perineural/lymphatic/vascular invasion. Previously, pre-operative RT was favored as it led to regression of tumor and improved overall survival (OS) relative to surgery alone. However, concerns about increases in operative morbidity with pre-operative compared to post-operative RT led to the comparison of these two treatment strategies in randomized trials. RTOG 73-03 randomized patients with operable SCCHN pre-operative RT (50 Gy) or post-operative RT (60 Gy). Higher doses of RT were used in the post-operative setting 
because of concerns that hypoxia in the surgical bed would decrease the efficacy of radiotherapy. This study found a 12\% improvement in locoregional control (LRC) in the post-operative treatment group with marked increase in failures in the pre-operative treatment group beyond two years ( $27 \%$ vs $8 \%$ ). There was no significant difference in overall survival or toxicity profiles between the two groups (Tupchong et al. 1991). Based on this study, post-operative therapy became the preferred regimen if both surgical therapy and radiotherapy were delivered.

Although radiotherapy improves outcomes compared to surgery alone, the combination of the two modalities in patients with locally advanced SCCHN yields a disappointing 5 year OS of about 30\% (El-Sayed and Nelson 1996). In an attempt to improve these outcomes, the EORTC (European Organisation for Research and Treatment of Cancer) and RTOG (Radiation Therapy Oncology Group) performed clinical trials evaluating the addition of concurrent sensitizing chemotherapy to regimens of surgery and radiotherapy (Bernier 2004 et al.; Cooper et al. 2004). Both groups completed randomized trials of concurrent cisplatin based chemotherapy and RT delivered in the post-operative setting to patients with risk factors for local recurrence (positive surgical margins, extracapsular extension of lymph node, lymphvascular invasion, perineural invasion). Patients enrolled on these trials were randomized to postoperative RT alone or to postoperative RT with concurrent cisplatin. Both studies found improved locoregional control and disease free survival in the patients that received concurrent cisplatin compared to those that received post-operative radiotherapy alone. Based on these two studies, post-operative RT with concurrent cisplatin has become standard of care for patients with high risk pathologic features (NCCN guidelines).

\section{Definitive Concurrent Chemotherapy and Radiation therapy}

Surgical therapy is not always employed for locally advanced SCCHN due to concerns of organ function or if a tumor is unresectable. In these patients, definitive radiotherapy was first used as a method for obtaining local control. The addition of chemotherapy to RT was explored in a number of randomized trials during the 1960's through the 1990's as a means to improve rates of overall survival and locoregional control compared to the rates obtained with radiotherapy alone. Because conflicting results were obtained in these studies, a large meta-analysis (MACH-NC) was performed that reviewed 63 randomized trials that evaluated the addition of chemotherapy to the management of these patients (Pignon et al. 2000). This meta-analysis was unable to show an OS benefit with neoadjuvant or adjuvant chemotherapy. An update of this meta-analysis added 24 more trials and found a survival benefit to concurrent chemotherapy both in the post-operative and definitive treatment settings (Pignon et al. 2007). More recently, multiple randomized Phase III trials have shown an improvement in OS and LRC when chemotherapy is added to radiotherapy for the definitive management of locally advanced SCCHN. Table 1 briefly summarizes several of these trials.

While the addition of chemotherapy to radiation therapy can improve disease control, it often increases the rate of mucositis and PEG tube requirements (Vokes et al. 2003; Cooper et al. 2004; Ang et al. 2005). A recent study has shown that the addition of chemotherapy to radiation therapy continues to increase the rate of Grade $2-3$ xerostomia (92\% vs. $37 \%$ (chemoradiation vs. radiation alone), Grade 3 mucositis (75\% vs. 51\%), Grade 3 dysphagia ( $82 \%$ vs. $48 \%$ ) and Grade 3 pain (29\% vs. 10\%) (Nuyts et al. 2008).

\section{Altered fractionation}

For patients with locally advanced SCCHN that receive definitive radiation, chemotherapy can improve both LRC and OS. However, chemotherapy can significantly increase the 
toxicity profile and thus may not be appropriate for patients with specific contraindications, such as preexisting renal dysfunction. Efforts to improve outcomes without chemotherapy in patients treated with radiotherapy have included the use of altered radiation fractionation schemes.

Radiation is commonly delivered in a single daily fraction over the course of weeks (ie. standard or conventional fractionation). Some subsets of tumors, such as SCCHN, have been found to grow rapidly. In order to combat this rapid growth some have explored the use of alternative fractionation schemes such as hyperfractionation and accelerated fractionation to deliver more radiation dose in a shorter time. Hyperfractionation regimens deliver many smaller fractions of radiation and exploit the difference in fractionation sensitivity between tumors and normal tissues. Accelerated fractionation regimens attempt to reduce tumor proliferation, which is a major cause of RT failure, by compressing the treatment schedule without major reductions in fraction size. Studies of altered fractionation schemes in patients with SCCHN have found improvements in local control at the cost of higher toxicity compared to conventional fractionation schemes (table 2).

It remains unclear if concurrent chemotherapy or altered fractionation approaches are the preferred method of treatment in patients that receive definitive RT for locally advanced SCCHN. Although toxicity is sizable with both approaches, local failures remain a concern. For this reason, additional studies have been completed that have evaluated the combination of hyperfractionation and chemotherapy, RTOG 0129. Additional studies will need to be completed to compare these approaches and define the optimal regimen based on disease control rates and toxicity. It is possible that treatment will need to be individualized based on both disease stage, the functional status of the patient, and the goals of therapy.

\section{Radiation Therapy and Targeted agents}

The development of agents that target specific pathways selectively active or upregulated in tumors has provided a potential mechanism for treatment that may have less toxicity than cytotoxic chemotherapy and thus may have less toxicity when combined with radiation. SCCHN has been shown to overexpress epidermal growth factor receptor (EGFR) (Mendelsohn and Baselga 2003; Hynes and Lane 2005). In addition, radiation is known to induce EGFR-mediated radioresistance signaling pathways (Bonner et al. 1994; Liang et al. 2003), suggesting that inhibition of EGFR may provide an attractive means of selectively sensitizing tumors to radiation. Cetuximab is an immunoglobulin monoclonal antibody to the EGFR ligand binding domain (Fan et al. 1993) and has been used in trials in conjunction with RT. Cetuximab was tested in this setting in a multinational randomized trial in which patients with stage III/IV oropharyngeal, hypopharyngeal, and laryngeal primary tumors were randomized to cetuximab with RT versus RT alone, the standard treatment at that time (Bonner et al. 2006). This study found that RT combined with cetuximab improved 3 year LRC and OS rates compared to those obtained with radiation alone (from 45 to 55\%). In addition to these encouraging results, there was no increase in mucosal toxicity with the addition of cetuximab to RT compared to RT alone, in stark contrast to the results observed with concurrent chemotherapy (Brizel et al. 1998). However, because this study tested RT alone as the control arm in a patient population in which concurrent RT and chemotherapy have became standard of care, the role of cetuximab as an alternative to chemotherapy has been questioned.

As discussed earlier, even with concurrent chemotherapy and RT, local recurrences continue to occur at unacceptable rates in patients with locally advanced SCCHN. Therefore, adding cetuximab to the current standard of cisplatin based concurrent chemotherapy and RT was proposed. The RTOG is currently evaluating the addition of cetuximab to concurrent cisplatin based chemotherapy and RT. Other targeted agents are being evaluated in clinical 
trials in combination with RT for patients with locally advanced SCCHN including Bevacizumab (Avastin).

\section{Technological Advances}

\section{IMRT}

Locally advanced SCCHN can be difficult to adequately treat secondary to its close proximity to many critical normal organs such as the brainstem, spinal cord, optic nerves, and optic chiasm (Chao et al. 2000; Nutting et al. 2001; Claus et al. 2002). Conventional radiation techniques used in the past have led to many unfortunate side effects that were permanent and severe, decreasing patients' quality of life (Scully and Epstein 1996; Harrison et al. 1997, Eisbruch et al. 2004). The advent of conformal therapy such as Intensity Modulated RT (IMRT) has allowed for precise application of increased dose to the tumor volume while sparing surrounding normal tissues from high radiation doses.

IMRT is a type of conformal RT that creates a high-dose volume that "conforms" around the desired target volume while minimizing the dose to critical normal tissues (Figure 1) (Gunderson and Tepper 2007). IMRT allows for sophisticated shaping of radiation dose with various techniques such as varying the radiation intensity within each beam. The use of dynamic multi-leaf collimators allows for dose intensity changes to be made or simultaneously administer integrated doses to different area during the same treatment. As opposed to 3D conformal RT, optimization of treatment beams is performed via computerized iteration (Liebel and Phillips 2005) which is often described as inverse treatment planning.

IMRT for locally advanced SCCHN allows sparing of the parotid glands compared to older techniques that severely affected parotid functioning (Figure 2). Parotid dysfunction can lead to impaired dental health due to the lack of serous salivary flow. Parotid sparing leads to an improvement in xerostomia over time after treatment (Eisbruch et al. 2001;Braaksma et al. 2003;Saarilahti et al. 2005). Additional areas to avoid with IMRT that may reduce long term xerostomia include uninvolved oral cavity (reflecting minor salivary gland contribution) (Eisbruch et al. 2001).

Another concern associated with definitive irradiation of the head and neck region is osteoradionecrosis (ORN) of the mandible, which can occur if high radiation doses are delivered to portions of the mandible, especially if that bone is damaged by infection (tooth abscess) or tumor. The incidence of ORN in patients receiving RT alone for SCCHN has been noted to be declining in recent decades: occurring prior to 1968 at a rate of $11.8 \%$, at 5.4\% from 1968 to 1992, and at 3\% after 1997 (Wahl 2006). A recent review of 176 SCCHN patients treated using IMRT reveals a lack of ORN at a median follow up of 35 months (Ben-David et al. 2007). This appears to be meaningful data as the majority of cases of ORN are seen within 2 years of treatment (Reuther et al. 2003). The proposed hypothesis for the lack of ORN in recent series is a combination of reduced mandibular dose using newer planning and delivery methods with associated improved oral health and meticulous prophylactic dental care.

Recent studies have delineated that pharyngeal constrictors and the supraglottic larynx often malfunction after intensive chemotherapy and RT which can lead to dysphagia and aspiration (Eisbruch et al. 2004). They found that using IMRT targeted to spare the above mentioned structures lead to decreased dysphagia without compromising treatment to the tumor (Eisbruch et al. 2004). This motivated a clinical trial to spare these swallowing structures which shows promise that reducing dose to those areas correlates to less dysphagia and aspiration (Feng et al. 2007). 


\section{Image guided Radiation Treatment}

Technologic advances have afforded radiation oncologists the ability to more accurately and precisely deliver radiation treatments. Image guided RT (IGRT) uses techniques such as on board imaging (daily localization) or to more accurately target tumor. This allows further refinements RT volumes to minimize the inclusion of uninvolved normal tissues.

In addition to the ability to accurately align patients for treatment, the use of newer imaging modalities may allow a more accurate definition of tumor volumes. Various imaging modalities have been studied to assist in target delineation such as ${ }^{1} \mathrm{H}$-MRI, BOLD effect and invasive hypoxia marker techniques such as ${ }^{3} \mathrm{H}$ labeled misonidazole (Hockel and Vaupel 2001). FMISO imaging has the largest existing body of experience for hypoxia imaging in head and neck cancers (Rajendran et al. 2006). ${ }^{18} \mathrm{~F}-\mathrm{FMISO}$ fluoromisonidazole 3-fluoro-1-(2'nitro-imidazolyl)-2-propanol is a hypoxia tracer that can be tagged with an appropriate label and its accumulation in hypoxic areas can be detected via positron emission tomography (PET) (Koh et al. 1992). FMISO PET scans are rapidly becoming the imaging modality of preference for investigation of target volume delineation for RT for head and neck cancers (Daisne et al. 2003). The incorporation of FMISO PET scans in RT planning remains investigational.

\section{Chemotherapeutic advances}

\section{Induction chemotherapy}

In the early 1980s, the use of induction chemotherapy for the treatment of patients with SCCHN was described as a method with the intended goal of decreasing distant metastases and increasing organ preservation by initiating systemic therapy early and by minimizing the disease that RT would need to eradicate. A few studies showed impressive response rates to induction chemotherapy and many groups adopted induction chemotherapy as standard of care (Harari 1997). A Phase III European study evaluated induction chemotherapy with cisplatin and 5FU followed by locoregional treatment or locoregional treatment alone. Among operable patients, there was no difference in OS at 5 and 10 years between the two groups however among inoperable patients, the OS at 5 and 10 years was $21 \%$ and $16 \%$ for the group who had received induction chemotherapy and $8 \%$ and $6 \%$ for those who had received RT alone (Merlano et al. 1996; Zorat et al. 2004). Other trials have studied the use of induction chemotherapy in patients with oropharyngeal cancer and found a statistically significant improvement in survival with the addition of chemotherapy prior to definitive chemoradiation (Domenge et al. 2000). Table 3 gives an overview of a few important induction chemotherapy trials and their outcomes.

While these findings are encouraging, there are many aspects of induction chemotherapy to consider when making treatment planning decisions (Eisbruch 2007). Chemotherapy alone is not curative, and after induction chemotherapy many patients refuse to move onto definitive chemoradiation due to the toxicity that they have already experienced or anticipate they will experience or because the bulk of their disease has decreased with induction chemotherapy. This unfortunately increases the likelihood of having locoregional failure.

Induction chemotherapy may lead to radiographic shrinkage of tumor but there are likely many residual subclinical tumor cells remaining. It is not clear whether radiotherapy volumes should be significantly altered in the setting of a major response or if this will result in an unacceptable rate of local failures. Of additional concern is the concept of accelerated repopulation after induction chemotherapy. The term accelerated repopulation describes the phenomenon by which certain human tumors, including head and neck cancers, begin to proliferate more rapidly after exposure to cytotoxic agents (Hall and Garcia 2005). If definitive chemoradiation is delayed until after the administration of induction 
chemotherapy, the surviving clonogens are repopulating at a faster rate and poses a theoretical impediment to the patient's chance of cure (Eisbruch 2007)

\section{Treatment related toxicity}

\section{Acute}

While there have been many advances in the management of SCCHN, treatment associated toxicities can lead to decreased QOL and the need for medical intervention (Epstein $e t$ al. 2001). Acute toxicities of RT and chemoradiotherapy occur during or shortly after treatment and are important to consider as they can lead to sub-optimal adherence to protocol therapy and unplanned treatment breaks. Common acute toxicities observed in patients with SCCHN that receive radiation as a component of their care include mucositis, radiation dermatitis, xerostomia, dysphagia, regional alopecia (with IMRT it is classically seen along the occipital region), hoarseness, transient ear discomfort, dysgeusia, and weight loss (Vissinck et al. 2003; Huguenin et al. 1999).

Mucositis is a common toxicity seen secondary to RT and can be the source of discomfort and pain resulting in dysphagia, odynophagia and weight loss (Trotti et al. 2003). This can lead to poor treatment compliance and thus poorer outcomes (Sonis 2004; Rosenthal et al. 2006). The rate of mucositis in patients who receive chemotherapy alone is stated to be about 40-60\% (Schubert et al. 1991; Woo et al. 1993; Sonis 1997). Patients who receive chemoradiation may have an incidence of mucotisits as high as $80-90 \%$ with somewhere between $30-60 \%$ of patients having severe (Grade 3 or 4) mucostitis (Giles et al. 2003, Trotti et al. 2003, Trotti et al. 2004).

Prophylactic and expectant care are critical in managing these toxicities. Multidisciplinary evaluations of patients with SCCHN should include a nutritional evaluation prior to the initiation of therapy. This is essential to optimize nutrition, provide education on particular foods or beverages that may cause an increase in symptoms (e.g. acidic beverages), and to help determine the need for prophylactic gastrostomy (PEG) tube placement to prevent unacceptable weight loss during therapy. Patients may also require the use of systemic analgesics, commonly opioid analgesics to help with the pain associated with mucositis (Kim et al. 1986; Saadeh 2005).

As mentioned above, the use of IMRT has altered the acute and chronic toxicity profile for many patients receiving this therapy. Although IMRT may spare certain tissues from radiation, it should be assumed that these patients will experience many of the same acute toxicities as spared structures often are those appreciated to have late toxicity, such as salivary glands. Organs such as skin, mucosa, and larynx that are associated with acute toxicities are often not spared with IMRT to an extent greater than that obtained with conventional planning (Sanguineti et al. 2004). It has been noted that salivary gland function can be maintained with IMRT without jeopardizing the local control rate in the treatment of locally advanced SCCHN (Saarilahti et al. 2005, Huang et al. 2008).

\section{Late side effects}

Late side effects due to radiation are thought to result from injury to stromal and supporting structures such as subcutaneous tissues and vasculature (Cooper et al. 1995) as well as due to ongoing inflammation and fibrosis (Bentzen 2006). In head and neck cancers the extent of long term complications are largely affected by total dose and fractionation scheme (Maciejewski et al. 1990). These effects are long lasting, often permanent, and are an unfortunate cause of long term morbidity. The combination of chemotherapy and radiation commonly results in xerostomia, loss of taste, telangiectasias (Figures 3, 4) subcutaneous fibrosis (Figure 4), skin and mucosal atrophy, loss of subcutaneous fat, skin discoloration, 
chronic alopecia in the radiation treatment field (Mossman 1983; Million and Cassisi 1994). Less common long-term treatment adverse events include: loss of hearing, chronic swallowing dysfunction and severe subcutaneous fibrosis (Million and Cassisi 1994). Rare late toxicities from RT include mandibular ORN, brain necrosis (unless patient has parotid or nasopharynx tumor), and cervical myelopathy ( $<1 \%$ incidence with restriction of spinal cord dose to $\leq 45$ Gy) (Lee et al. 1988; Marcus and Miller 1990; Reuther et al. 2003).

Hypothyroidism is commonly seen among patients receiving head and neck radiotherapy; this association was noted as early as the 1920s (Grover et al. 1929). However, the development of hypothyroidism has not been significantly influenced by the use of chemotherapy alone (Posner et al. 1985; Littley et al. 1990; Weissler and Berry 1991; Bhandare et al. 2007). While some sources note that the incidence can be as high as $50 \%$ (Kuten et al. 1996) most sources note the incidence is about 20-30\% (Jereczek-Fossa et al. 2004). The development of hypothyroidism is dependent on the dose of radiation delivered to the thyroid gland (Bhandare et al. 2007).

Xerostomia is a common complaint of SCCHN patients. During therapy, saliva becomes and scant and viscous. This is not only uncomfortable for the patient but can lead to subsequent sequelae such as oral infections, difficulty speaking and dental caries. Prior to the advent of IMRT, the rate of xerostomia ranged from about 94-100\% in patients with SCCHN treated with radiotherapy (Ramirez-Amador et al. 1997; Hughes et al. 2000; Kies et al. 2001).

As has been discussed previously in regards to IMRT, the incidence of mandibular ORN has been drastically declined this is thought to be a combination of decreased dose with the use of IMRT and improved prophylactic dental care. Recent attention to survivorship issues has led to the realization that the toxicities of these therapies can have a significant impact on the long term quality of life of survivors (Trotti et al. 2007).

\section{Radiation protectors and mitigation of established toxicity}

A radioprotector is defined as a chemical compound that protects against radiation damage in normal cells but does not provide similar protection to tumor cells (Leibel and Phillips 2004; Hall and Garcia 2005). To be effective, radioprotectors must be present before or shortly after radiation. An alternative to radioprotectors are effective therapies to deal with toxicity once it develops.

\section{Amifostine}

Amifostine is a thiophosphate that was first synthesized by the US Army to protect soldiers against ionizing radiation. It is a prodrug which is hydrolyzed in vivo by alkaline phosphatase to its active cytoprotective thiol metabolite which acts by scavenging free radicals and accumulating in epithelial tissues. The selective protection of normal tissues is believed to be due to higher alkaline phosphatase activity, higher $\mathrm{pH}$, and vascular permeation of normal tissues. In a study involving 315 patients who received RT alone (60 to $70 \mathrm{~Gy}$ ) for treatment of SCCHN, patients were randomly assigned to amifostine or no amifostine (Brizel et al. 2000). In this study amifostine reduced the incidence of significant acute xerostomia from 78 to 51 percent, and the incidence of significant chronic xerostomia at 12 months from 57 to 34 percent. There was no impact on mucositis or on tumor control at two years (Brizel and Wasserman 2004). Currently, most centers with IMRT prefer to use this approach to reduce the risk of xerostomia due to the difficulty in administration of amifostine (frequent hypotension, the need for fluid boluses, and the requirement for timing close to the radiation delivery). IMRT can be used to spare the parotid gland contralateral to the tumor and potentially spare part of the ispsilateral parotid gland as well (Eisbruch et al. 2004, Saarilahti et al. 2005). 
Palifermin

Palifermin is a recombinant keratinocyte growth factor (KGF) that has been evaluated in clinical trials as a method to reduce mucositis in patients receiving chemoradiation for SCCHN. KGF stimulates the growth of cells in certain tissues such as the skin and the surface layer of the mouth, stomach, and colon, helping to maintain the normal structure of these tissues and assists in the repair of damaged cells. Palifermin attaches to KGF receptors and stimulates cell growth. A multi-national study was recently reported that evaluated palifermin versus placebo in patients with advanced SCCHN who underwent concurrent chemotherapy and RT. This study showed that palifermin was more effective in reducing mucositis in patients who received hyperfractionated RT. Palifermin is known to be well tolerated but it does not impact the morbidity among all patients receiving chemoradiation (Brizel 2008).

\section{Salagen}

Salagen, pilocarpine, is a muscarinic alkaloid obtained from the leaves of tropical American shrubs from the genus Pilocarpus. It is a non-selective muscarinic receptor agonist in the parasympathetic nervous system, which acts therapeutically at the muscarinic acetylcholine receptor M3 (Spalding et al. 2002). Recently, the results for a prospective, double blinded, placebo controlled trial of 170 SCCHN patients who received RT with or without the use of pilocarpine were published. Patients who received concomitant pilocarpine did not have improved parotid flow or patient reported complaints of xerostomia. However, they did find that in a subgroup of patients who received a mean parotid dose $>40 \mathrm{~Gy}$ and received pilocarpine had improved function of their parotid gland (Burlage et al. 2008). As pilocarpine works on the acetylcholine receptor, it is not unexpected that adverse effects include excessive sweating, urinary frequency, lacrimation, and rhinitis.

\section{Pentoxyfilline and Vitamin E}

Pentoxifylline (PTX) is a phosphodiesterase inhibitor that causes vasodilation, improves erythrocyte flexibility, and enhances blood flow that has been found to reduce radiation induced fibrosis (Okunieff et al. 2004). It has also been shown to heal radiation-induced soft tissue necrosis significantly faster (Dion et al. 1990). Vitamin E has been used alone to treat radiation induced fibrosis as other agents such as superoxide dismutase that has antioxidant activity has been efficacious in treatment of fibrosis and was found to be minimally effective (Baillet 1997). Thus a Phase II trial combining both pentoxifylline and vitamin E was performed and was found to regress radiation induced fibrosis surface (Delanian et al. 1999). This led to a randomized study of the use of pentoxifylline and vitamin $E$ versus placebo and they found a significant regression of radiation induced fibrosis (Delanian et al. 2003). Currently there is a clinical trial looking at the effect of these two agents in the treatment of late radiation effects and findings in this trial may further support the recent promising results (Levin 2005).

\section{AdhAQP1}

Xerostomia is a common toxicity in patients receiving RT for locally advanced SCCHN. As mentioned above, SCCHN irradiation can cause damage to parotid glands leading to xerostomia, dry mouth, and subsequent tooth decay, infections and difficulty swallowing. One investigational method for increasing salivary output in patients with xerostomia, gene transfer, is currently in clinical trials. The human aquaporin-1 gene (hAQP1) is a plasma membrane protein that facilitates water movement across cell layers. In preclinical studies AdhAQP1 recombinant serotype 5 adenoviral has been shown to restore salivary flow and it is currently being studied to see the safety of this dose in humans (Baum et al. 2004) 


\section{Conclusions}

Treatment of SCCHN has evolved in the last few decades leading to improved tumor control. Although early stage SCCHN patients have a good prognosis, patients with advanced staged cancers continue to have an overall poor prognosis. For locally advanced SCCHN, a number of options exist including surgical resection followed by radiation or chemoradiation or definitive RT with or without chemotherapy. The use of chemotherapy may increase local control and survival but may be associated with more significant acute and late toxicities. Advances such as the use of induction chemotherapy and targeted therapy show promise to further improve outcomes.

While significant improvements in disease outcomes have occurred, toxicity remains a major consideration for all patients with SCCHN that receive RT. The use of newer modalities such as IMRT and IGRT has led to less chronic normal tissue damage in certain subsets of patients. Targeted therapies may offer similar benefits to chemotherapy without the associated toxicities. Continued research is needed to define new agents to use as radioprotectors and to define the appropriate use of those already identified. Perhaps most importantly, evaluation of survivors of cancer therapy will provide a more accurate estimation of rates of late toxicity and the impact of these toxicities on QOL.

\section{References}

Adelstein DJ, Tan EH, Lavertu P. Treatment of head and neck cancer: The role of chemotherapy. Crit Rev Oncol Hematol. 1996; 24:97-116. [PubMed: 8889368]

Adelstein DJ, Li Y, Adams GL, et al. An intergroup phase III comparison of standard radiation therapy and two schedules of concurrent chemoradiotherapy in patients with unresectable squamous cell head and neck cancer. J Clin Oncol. 2003; 21(1):92-8. [PubMed: 12506176]

Al-Sarraf M, LeBlanc M, Giri PG, et al. Chemoradiotherapy versus radiotherapy in patients with advanced nasopharyngeal cancer: phase III randomized Intergroup study 0099. J Clin Oncol. 1998; 16(4):1310-7. [PubMed: 9552031]

Ang KK, Harris J, Garden AS, et al. Concomitant boost radiation plus concurrent cisplatin for advanced head and neck carcinomas: Radiation Therapy Oncology Group phase II trial 99-14. J Clin Oncol. 2005; 23:3008-3015. [PubMed: 15860857]

Greene, FL.; Page, DL.; Fleming, ID., et al., editors. AJCC (American Joint Committee on Cancer). Manual for Staging of Cancer. 6. Springer-Verlag; New York: 2002.

Baillet F. Alpha-tocopherol treatment of radio-fibrosis post-brachytherapy for breast cancer. Radiother Oncol. 1997; 43:S3. abstr 9.

Baum BJ, Voutetakis A, Wang J. Salivary glands: novel target sites for gene therapeutics. Trends Mol Med. 2004; 10(12):585-90. [PubMed: 15567328]

Ben-David MA, Diamante M, Radawski JD, et al. Lack of osteoradionecrosis of the mandible after intensity-modulated radiotherapy for head and neck cancer: likely contributions of both dental care and improved dose distributions. Int J Radiat Oncol Biol Phys. 2007; 68(2):396-402. [PubMed: 17321069]

Bentzen SM. Preventing or reducing late side effects of radiation therapy: radiobiology meets molecular pathology. Nat Rev Cancer. 2006; 6(9):702-13. [PubMed: 16929324]

Bernier J, Domenge C, Ozsahin M, et al. Postoperative irradiation with or without concomitant chemotherapy for locally advanced head and neck cancer. N Engl J Med. 2004; 350(19):1945-52. [PubMed: 15128894]

Bhandare N, Kennedy L, Malyapa RS, et al. Primary and central hypothyroidism after radiotherapy for head-and-neck tumors. Int J Radiat Oncol Biol Phys. 2007; 68(4):1131-9. [PubMed: 17446000]

Bonner JA, Harari PM, Giralt J, et al. Radiotherapy plus cetuximab for squamous-cell carcinoma of the head and neck. N Engl J Med. 2006; 354(6):567-78. [PubMed: 16467544] 
Bonner JA, Maihle NJ, Folven BR, et al. The interaction of epidermal growth factor and radiation in human head and neck squamous cell carcinoma cell lines with vastly different radiosensitivities. Int J Radiat Oncol Biol Phys. 1994; 29:243-7. [PubMed: 8195014]

Braaksma MM, Wijers OB, van Sornsen de Koste JR, et al. Optimisation of conformal radiation therapy by intensity modulation: Cancer of the larynx and salivary gland function. Radiother Oncol. 2003; 66:291-302. [PubMed: 12742269]

Brizel DM, Albers ME, Fisher SR, et al. Hyperfractionated irradiation with or without concurrent chemotherapy for locally advanced head and neck cancer. N Engl J Med. 1998; 338(25):1798804. [PubMed: 9632446]

Brizel DM, Wasserman TH, Henke M, et al. Phase III randomized trial of amifostine as a radioprotector in head and neck cancer. J Clin Oncol. 2000; 18(19):3339-45. [PubMed: 11013273]

Brizel DM, Wasserman T. The influence of intravenous amifostine on xerostomia and survival during radiotherapy for head and neck cancer: Two year follow-up of a prospective randomized trial (abstract). Proc Am Soc Clin Oncol. 2004; 23:495.

Brizel DM. Phase II study of palifermin and concurrent chemoradiation in head and neck squamous cell carcinoma. J Clin Oncol. 2008; 26(15):2489-96. [PubMed: 18487568]

Burlage FR, Roesink JM, Kampinga HH. Protection of salivary function by concomitant pilocarpine during radiotherapy: a double-blind, randomized, placebo-controlled study. Int J Radiat Oncol Biol Phys. 2008; 70(1):14-22. [PubMed: 17869018]

Denis F, Garaud P, Bardet E, et al. Final results of the 94-01 French Head and Neck Oncology and Radiotherapy Group randomized trial comparing radiotherapy alone with concomitant radiochemotherapy in advanced-stage oropharynx carcinoma. J Clin Oncol. 2004; 22(1):69-76. [PubMed: 14657228]

Chao KS, Low D, Perez CA, et al. Intensity-modulated radiation therapy in head and neck cancers: The Mallinckrodt experience. Int J Cancer. 2000; 90:92-103. [PubMed: 10814959]

Claus F, Duthoy W, Boterberg T, et al. Intensity modulated radiation therapy for oropharyngeal and oral cavity tumors: clinical use and experience. Oral Oncol. 2002; 38(6):597-604. [PubMed: 12167438]

Cooper JS, Fu K, Marks J, et al. Late effects of radiation therapy in the head and neck region. Int J Radiat Oncol Biol Phys. 1995; 31:1141-64. [PubMed: 7713779]

Daisne JF, Sibomana M, Bol A, et al. Evaluation of a multimodality image (CT, MRI, and PET) coregistration procedure on phantom and head and neck cancer patients: accuracy, reproducibility and consistency. Radiother Oncol. 2003; 69:237-45. [PubMed: 14644482]

Delanian S, Balla-Mekias S, Lefaix JL. Striking regression of chronic radiotherapy damage in a clinical trial of combined pentoxifylline and tocopherol. J Clin Oncol. 1999; 17:3283-3290. [PubMed: 10506631]

Delanian S, Porcher R, Balla-Mekias S, et al. Randomized, placebo-controlled trial of combined pentoxifylline and tocopherol for regression of superficial radiation-induced fibrosis. J Clin Oncol. 2003; 21(13):2545-50. [PubMed: 12829674]

Dion M, Hussey D, Doornbos J, et al. Preliminary results of a pilot study of pentoxifylline in the treatment of late radiation soft tissue necrosis. Int J Radiat Oncol Biol Phys. 1990; 19:401-407. [PubMed: 2394619]

Domenge C, Hill C, Lefebvre JL, et al. Randomized trial of neoadjuvant chemotherapy in oropharyngeal carcinoma. French Groupe d'Etude des Tumeurs de la Tête et du Cou (GETTEC). Br J Cancer. 2000; 83(12):1594-8. [PubMed: 11189100]

Eisbruch A, Kim HM, Terrell HE, et al. Xerostomia and its predictors following parotid-sparing irradiation of head-and-neck cancer. Int J Radiat Oncol Biol Phys. 2001; 50(3):695-704. [PubMed: 11395238]

Eisbruch A, Schwartz M, Rasch C, et al. Dysphagia and aspiration after chemoradiotherapy for headand-neck cancer: which anatomic structures are affected and can they be spared by IMRT? Int J Radiat Oncol Biol Phys. 2004; 60(5):1425-39. [PubMed: 15590174]

Eisbruch A. Commentary: induction chemotherapy for head and neck cancer: hypothesis-based rather than evidence-based medicine. The Oncologist. 2007; 12(8):975-7. [PubMed: 17766657] 
El-Sayed S, Nelson N. Adjuvant and adjunctive chemotherapy in the management of squamous cell carcinoma of the head and neck region. A meta-analysis of prospective and randomized trials. J Clin Oncol. 1996; 14:838-847. [PubMed: 8622032]

Epstein JB, Robertson M, Emerton S, et al. Quality of life and oral function in patients treated with radiation therapy for head and neck cancer. Head Neck. 2001; 23(5):389-98. [PubMed: 11295813]

Fan Z, Masui H, Altas I, et al. Blockade of epidermal growth factor receptor function by bivalent and monovalent fragments of 225 anti-epidermal growth factor receptor monoclonal antibodies. Cancer Res. 1993; 53:4322-4328. [PubMed: 8364927]

Feng FY, Kim HM, Lyden TH, et al. Intensity-modulated radiotherapy of head and neck cancer aiming to reduce dysphagia: early dose-effect relationships for the swallowing structures. Int J Radiat Oncol Biol Phys. 2007; 68(5):1289-98. [PubMed: 17560051]

Forastiere AA, Goepfert H, Maor M, et al. Concurrent chemotherapy and radiotherapy for organ preservation in advanced laryngeal cancer. N Engl J Med. 2003; 349(22):2091-8. [PubMed: 14645636]

Fu KK, Pajak TF, Trotti A, et al. A Radiation Therapy Oncology Group (RTOG) phase III randomized study to compare hyperfractionation and two variants of accelerated fractionation to standard fractionation radiotherapy for head and neck squamous cell carcinomas: first report of RTOG 9003. Int J Radiat Oncol Biol Phys. 2000; 48(1):7-16. [PubMed: 10924966]

Giles FJ, Miller CB, Hurd DD, et al. A phase III, randomized, double-blind, placebo-controlled, multinational trial of iseganan for the prevention of oral mucositis in patients receiving stomatotoxic chemotherapy (PROMT-T trial). Leuk Lymphoma. 2003; 44:1165-1172. [PubMed: 12916869]

Grover EA, Christie AC, Merritt EA, et al. Roentgen radiation in the treatment of hyperthyroidism: A statistical evaluation based on 305 cases. JAMA. 1929:1730-1734.

Gunderson, LL.; Tepper, JE. Head and Neck Tumors, Clinical Radiation Oncology. Second Edition. Philadelphia: Elsevier; 2007. p. 629-852.

Hall, EJ.; Giaccia, AJ. Radioprotectors, Radiosensitizers and Bioreductive Drugs, Radiobiology for the Radiologist. sixth edition. Philadelphia: Lippincott Williams\&Wilkins; 2006. p. 129-134.p. 419-431.

Harari PM. Why has induction chemotherapy for advanced head and neck cancer become a United States community standard of practice? J Clin Oncol. 1997; 15:2050-2055. [PubMed: 9164217]

Harrison LB, Zelefsky MJ, Pfister DG, et al. Detailed quality of life assessment in patients treated with primary radiotherapy for squamous cell cancer of the base of the tongue. Head Neck. 1997; 19(3): 169-75. [PubMed: 9142514]

Hockel M, Vaupel P. Tumor hypoxia: definitions and current clinical, biologic, and molecular aspects. J Natl Cancer Inst. 2001; 93(4):266-76. [PubMed: 11181773]

Horiot JC, Le Fur R, N'Guyen T, et al. Hyperfractionation versus conventional fractionation in oropharyngeal carcinoma: final analysis of a randomized trial of the EORTC cooperative group of radiotherapy. Radiother Oncol. 1992; 25(4):231-41. [PubMed: 1480768]

Horiot JC, Bontemps P, van den Bogaert W, et al. Accelerated fractionation (AF) compared to conventional fractionation (CF) improves loco-regional control in the radiotherapy of advanced head and neck cancers: results of the EORTC 22851 randomized trial. Radiother Oncol. 1997; 44(2):111-21. [PubMed: 9288839]

Huang K, Xia P, Chuang C, et al. Intensity-modulated chemoradiation for treatment of stage III and IV oropharyngeal carcinoma: the University of California-San Francisco experience. Cancer. 2008 June 2. epub ahead of print.

Hughes PJ, Scott PM, Kew J, et al. Dysphagia in treated nasopharyngeal cancer. Head Neck. 2000; 22:393-97. [PubMed: 10862024]

Huguenin PU, Taussky D, Moe K, et al. Quality of life in patients cured from a carcinoma of the head and neck by radiotherapy: The importance of the target volume. Int J Radiat Oncol Biol Phys. 1999; 45:47-52. [PubMed: 10477005]

Hynes NE, Lane HA. ERBB receptors and cancer: the complexity of targeted inhibitors. Nat Rev Cancer. 2005; 5:341-54. Erratum, Nat Rev Cancer 2005;5:580. [PubMed: 15864276] 
Jemal A, Siegel R, Ward E, et al. Cancer statistics, 2007. CA Cancer J Clin. 2007; 67:43-66. [PubMed: 17237035]

Jereczek-Fossa BA, Alterio D, Jassem J, et al. Radiotherapy induced thyroid disorders. Cancer Treat Rev. 2004; 30:369-384. [PubMed: 15145511]

Levin W. The Use of Pentoxifylline and Vitamin E in the Treatment of Late Radiation Related Injuries. Clinicaltrials.gov identifier: NCT00188552.

Kies MS, Haraf DJ, Rosen F, et al. Concomitant infusional paclitaxel and fluorouracil, oral hydroxyurea, and hyperfractionated radiation for locally advanced squamous head and neck cancer. J Clin Oncol. 2001; 19:1961-69. [PubMed: 11283128]

Kim JH, Chu FC, Lakshmi V, et al. Benzydamine $\mathrm{HCl}$, a new agent for the treatment of radiation mucositis of the oropharynx. Am J Clin Oncol. 1986; 9:132-34. [PubMed: 3521255]

Koh WJ, Rasey JS, Evans ML, et al. Imaging of hypoxis in human tumors with [F-18]Fluoromisonidazole. Int J Radiat Oncol Biol Phys. 1992; 22:199-212. [PubMed: 1727119]

Kuten A, Lubochitski R, Fishman G, et al. Postradiotherapy hypothyroidism: Radiation dose response and chemotherapeutic radiosensitization at less than 40 Gy. J Surg Oncol. 1996; 61:281-283. [PubMed: 8627999]

Lee AWN, Ng SH, Ho JHC, et al. Clinical diagnosis of late temporal lobe necrosis following radiation therapy for nasopharyngeal carcinoma. Cancer. 1988; 61:1535-1542. [PubMed: 3349419]

Leibel, SA.; Phillips, T. Textbook of Radiation Oncology. Second Edition. Philadelphia: Saunders; 2004.

Lefebvre JL, Chevalier D, Luboinski B, et al. Larynx preservation in pyriform sinus cancer: preliminary results of a European Organization for Research and Treatment of Cancer phase III trial. EORTC Head and Neck Cancer Cooperative Group. J Natl Cancer Inst. 1996; 88(13):890-9. [PubMed: 8656441]

Levin W. The Use of Pentoxifylline and Vitamin E in the Treatment of Late Radiation Related Injuries. ClinicalTrials.gov identifier: NCT00188552. 2005

Liang K, Ang KK, Milas L, et al. The epidermal growth factor receptor mediates radioresistance. Int J Radiat Oncol Biol Phys. 2003; 57:246-54. [PubMed: 12909240]

Littley MD, Shalet SM, Beardwell CG. Radiation and hypothalamic-pituitary function. Baillieres Clin Endocrinol Metab. 1990; 4:147-175. [PubMed: 2202287]

Maciejewski B, Withers HR, Taylor JMG, et al. Dose fractionation and regeneration in radiotherapy for cancer of the oral cavity and oropharynx. Part 2. Normal tissue response: Acute and late effects. Int J Radiat Oncol Biol Phys. 1990; 18:101-111. [PubMed: 2298613]

Marcus RB, Million RR. The incidence of myelitis after irradiation of the cervical spinal cord. Int J Radiat Oncol Biol Phys. 1990; 19:3-8. [PubMed: 2380091]

Mendelsohn J, Baselga J. Status of epidermal growth factor receptor antagonists in the biology and treatment of cancer. J Clin Oncol. 2003; 21:2787-99. [PubMed: 12860957]

Merlano M, Benasso M, Corvò R, et al. Five-year update of a randomized trial of alternating radiotherapy and chemotherapy compared with radiotherapy alone in treatment of unresectable squamous cell carcinoma of the head and neck. J Natl Cancer Inst. 1996; 88(9):583-9. [PubMed: 8609658]

Million, RR.; Cassisi, NJ. The effect of Radiation on Normal Tissues of the Head and Neck, Management of Head and Neck Cancer A multidisciplinary approach. Second Edition. Philadelphia: J.B. Lippincott Company; 1994. p. 245-290.

Mossman KL. Quantitative radiation dose-response relationships for normal tissues in man: II. Response of the salivary glands during radiotherapy. Radiat Res. 1983; 95:392-398. [PubMed: 6611856]

Nutting C, Convery DJ, Cosgrove VP, et al. Improvements in target coverage and reduced spinal cord irradiation using intensity-modulated radiotherapy (IMRT) in patients with carcinoma of the thyroid gland. Radiother Oncol. 2001; 60:173-180. [PubMed: 11439212]

Nuyts S, Dirix P, Clement PM, et al. Impact of Adding Concomitant Chemotherapy to Hyperfractionated Accelerated Radiotherapy for Advanced Head-and-Neck Squamous Cell Carcinoma. Int J Radiat Oncol Biol Phys. 2008 Aug 14. Epub ahead of print. 
Okunieff P, Augustine E, Hicks JE, et al. Pentoxifylline in the treatment of radiation-induced fibrosis. J Clin Oncol. 2004; 22:2207-2213. [PubMed: 15169810]

Pignon JP, Bourhis J, Domenge C, et al. Chemotherapy added to locoregional treatment for head and neck squamous-cell carcinoma: three meta-analyses of updated individual data. Lancet. 2000; 355:949-955. [PubMed: 10768432]

Pignon JP, le Maître A, Bourhis J. MACH-NC Collaborative Group. Meta-Analyses of Chemotherapy in Head and Neck Cancer (MACH-NC): an update. Int J Radiat Oncol Biol Phys. 2007; 69(2 Suppl):S112-4. [PubMed: 17848275]

Posner MR, Weichselbaum RR, Fitzgerald TJ, et al. Treatment complications after sequential combination chemotherapy and radiotherapy with or without surgery in previously untreated squamous cell carcinoma of the head and neck. Int J Radiat Oncol Biol Phys. 1985; 11:1887-1893. [PubMed: 2414254]

Rajendran JG, Wilson DC, Conrad EU, et al. $\left[{ }^{18} \mathrm{~F}\right] \mathrm{FMISO}$ and $\left[{ }^{18} \mathrm{~F}\right] \mathrm{FDG}$ PET imaging in soft tissue sarcomas: correlation of hypoxia, metabolism and VEGF expression. J Nuc Med Mol Imag. 2003; 30(5):695-704.

Ramirez-Amador V, Silverman S Jr, Mayer P, et al. Candidal colonization and oral candidiasis in patients undergoing oral and pharyngeal radiation therapy. Oral Surg Oral Med Oral Pathol Oral Radiol Endod. 1997; 84:149-53. [PubMed: 9269016]

Reuther T, Schuster T, Mende U, et al. Osteoradionecrosis of the jaws as a side effect of radiotherapy of head and neck tumour patients-A report of a thirty year retrospective review. Int J Oral Maxillofac Surg. 2003; 32:289-295. [PubMed: 12767877]

Rosenthal DI, Lewin JS, Eisbruch A. Prevention and treatment of dysphagia and aspiration after chemoradiation for head and neck cancer. J Clin Oncol. 2006; 24:2636-2643. [PubMed: 16763277]

Saadeh CE. Chemotherapy-and radiotherapy-induced oral mucositis: review of preventive strategies and treatment. Pharmacotherapy. 2005; 25:540-54. [PubMed: 15977916]

Saarilahti K, Kouri M, Collan J, et al. Intensity modulated radiotherapy for head and neck cancer: evidence for preserved salivary gland function. Radiother Oncol. 2005; 74(3):251-8. [PubMed: 15763305]

Sanguineti G, Sosa M, Culp L, et al. Is it feasible to spare part of the mucosa with IMRT and does it matter. Int J Radiat Oncol Biol Phys. 2004; 60:S517-S518.

Schubert MM, Sullivan KMJ, Truelove EL. Head and neck complication of bone marrow transplantation. Developmental Oncology. 1991; 36:401-427.

Scully C, Epstein JB. Oral health care for the cancer patient. Eur J Cancer B Oral Oncol. 1996; 32B(5): 281-92. [PubMed: 8944831]

Sonis, ST. Oral complications. In: Holland, JF., et al., editors. Cancer Medicine. 4. Philadelphia: Willams \& Wilkins; 1997. p. 3255-3264.

Sonis ST. The pathobiology of mucositis. Nat Rev Cancer. 2004; 4:277-284. [PubMed: 15057287]

Soo KC, Tan EH, Wee J, et al. Surgery and adjuvant radiotherapy vs concurrent chemoradiotherapy in stage III/IV nonmetastatic squamous cell head and neck cancer: a randomised comparison. Br J Cancer. 2005; 93(3):279-86. [PubMed: 16012523]

Spalding TA, Trotter C, Skjaerbaek N, et al. Discovery of an ectopic activation site on the M(1) muscarinic receptor. Mol Pharmacol. 2002; 61:1297-1302. [PubMed: 12021390]

The Department of Veteran's Affairs Laryngeal Cancer Study Group. Induction chemotherapy plus radiation compared with surgery plus radiation in patients with advanced laryngeal cancer. $\mathrm{N}$ Engl J Med. 1991; 324:1685-1690. [PubMed: 2034244]

Titcomb CP. High incidence of nasopharyngeal carcinoma in Asia. J Insur Med. 2001; 33(3):235-8. [PubMed: 11558403]

Trotti A, Bellm LA, Epstein JB, et al. Mucositis incidence, severity and associated outcomes in patients with head and neck cancer receiving radiotherapy with or without chemotherapy: a systematic literature review. Radiother Oncol. 2003; 66(3):253-62. [PubMed: 12742264]

Trotti A, Garden A, Warde P, et al. A multinational, randomized phase III trial of iseganan $\mathrm{HCl}$ oral solution for reducing the severity of oral mucositis in patients receiving radiotherapy for head-andneck malignancy. Int J Radiat Oncol Biol Phys. 2004; 58:674-681. [PubMed: 14967419] 
Trotti A, Colevas AD, Setser A, et al. Patient-reported outcomes and the evolution of adverse event reporting in oncology. J Clin Oncol. 2007; 25(32):5121-7. [PubMed: 17991931]

Tupchong L, Scott CB, Blitzer PH, et al. Randomized study of preoperative versus postoperative radiation therapy in advanced head and neck carcinoma: long-term follow-up of RTOG study 73-03. Int J Radiat Oncol Biol Phys. 1991; 20(1):21-28. [PubMed: 1993628]

Vissink A, Jansma J, Spijkervet FK, et al. Oral sequelae of head and neck radiotherapy. Crit Rev Oral Biol Med. 2003; 14:199-212. [PubMed: 12799323]

Vokes EE, Weichselbaum RR, Lippman SM, et al. Head and neck cancer. N Engl J Med. 1993; 328:184-194. [PubMed: 8417385]

Vokes EE, Stenson K, Rosen FR, et al. Weekly carboplatin and paclitaxel followed by concomitant paclitaxel, fluorouracil, and hydroxyurea chemoradiotherapy: Curative and organ-preserving therapy for advanced head and neck caner. J Clin Oncol. 2003; 21:320-326. [PubMed: 12525525]

Wahl MJ. Osteoradionecrosis prevention myths. Int J Radiat Oncol Biol Phys. 2006; 64:661-669. [PubMed: 16458773]

Weissler MC, Berry BW. Thyroid-stimulating hormone levels after radiotherapy and combined therapy for head and neck cancer. Head Neck. 1991; 13:420-423. [PubMed: 1938359]

Woo SB, Sonis ST, Monopoli MM, et al. A longitudinal study of oral ulcerative mucositis in bone marrow transplant recipients. Cancer. 1993; 72:1612-1617. [PubMed: 8348492]

Zorat PL, Paccagnella A, Cavaniglia G, et al. Randomized phase III trial of neoadjuvant chemotherapy in head and neck cancer: 10-year follow-up. J Natl Cancer Inst. 2004; 96(22):1714-7. [PubMed: 15547184] 


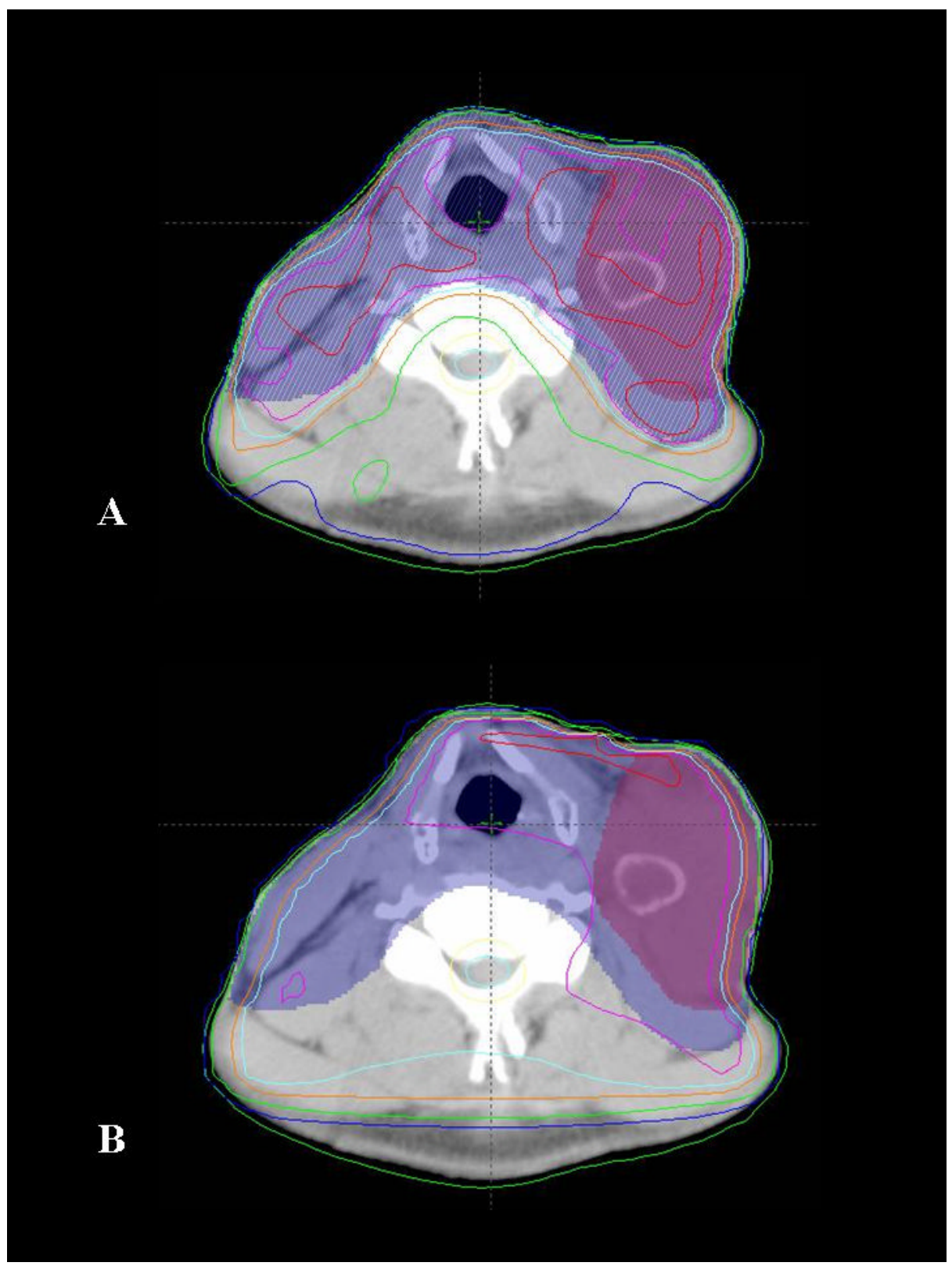

Figure 1.

Comparison of IMRT and 3D conformal radiotherapy plans for a patient with a large Level III tumor bearing lymph node. A) Axial section depicting the isodoses delivered with the IMRT plan. B) Axial section at the same anatomic level for the same patient with 3D conformal treatment planning. Note that the high radiation dose is not tightly conformed about the area of interest resulting in higher doses to structures such as the larynx. Shaded areas represent target volumes and lines represent radiation dose levels (isodose lines). Purple shaded area $=$ gross tumor, blue shaded area $=$ area at risk for spread of microscopic disease. Red line $=105 \%$ isodose line, magenta $=100 \%$, light blue $=95 \%$, dark blue $=50 \%$. 


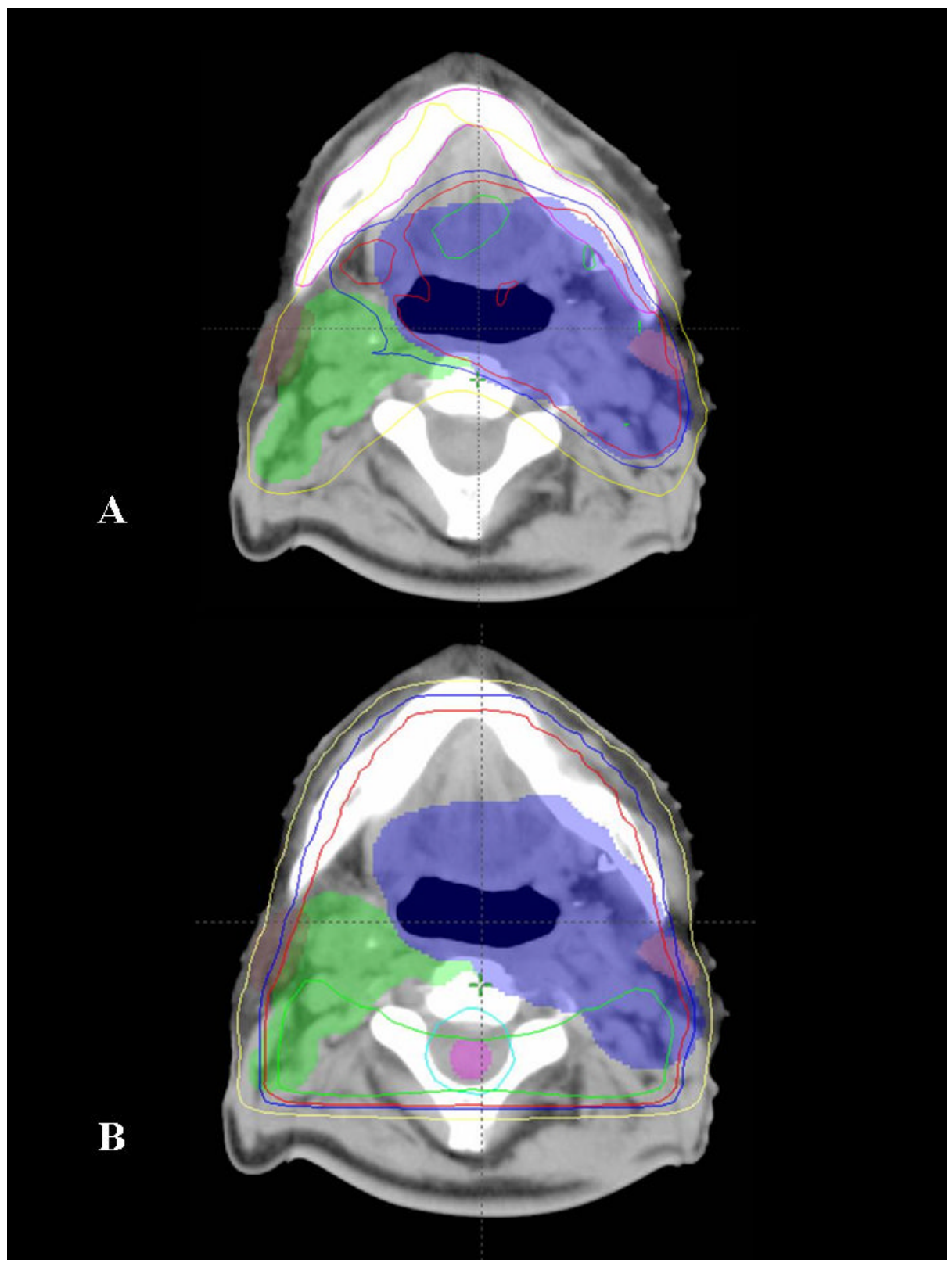

Figure 2.

Comparison of IMRT and 3D conformal radiotherapy plans for a patient with an oropharyngeal primary tumor. A) Axial section depicting the isodoses delivered with the IMRT plan. B) Axial section at the same anatomic level for the same patient with 3D conformal treatment planning. Note that the high radiation dose is not tightly conformed about the area of interest resulting in higher doses to structures such as the spinal cord, parotid, and uninvolved normal tissues. Shaded areas represent target volumes and lines represent radiation dose levels (isodose lines). Blue shaded area $=$ gross tumor and involved lymph nodes, green shaded area $=$ lymph nodes at risk. Green line $=105 \%$ isodose line, red line $=100 \%$, blue $=95 \%$ and yellow $=75 \%$. 


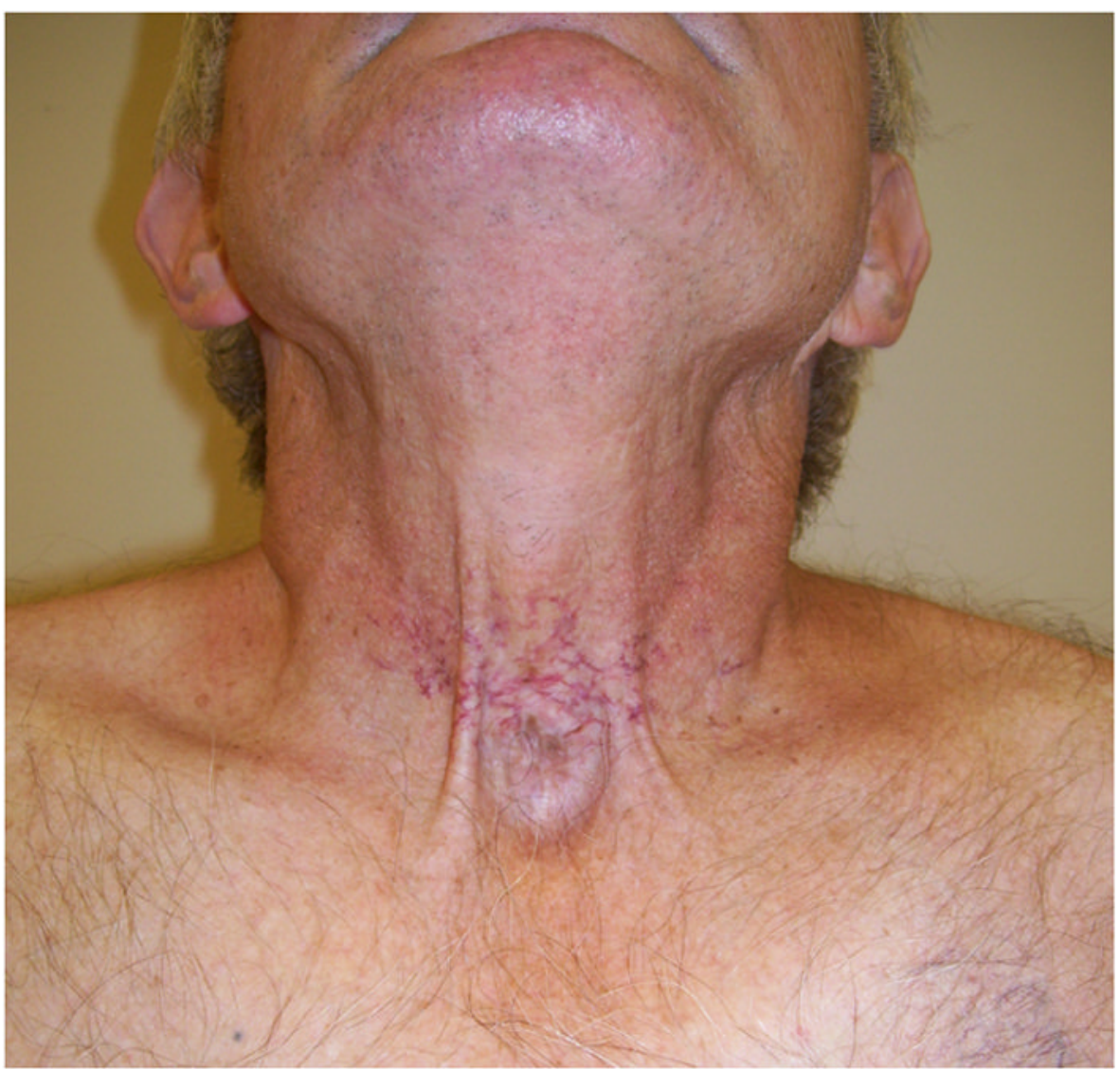

Figure 3.

A 66 year old man with history of radiation treatment for cancer of the larynx with evidence of telangiectasias on his anterior neck surrounding the site of his prior tracheostomy. 


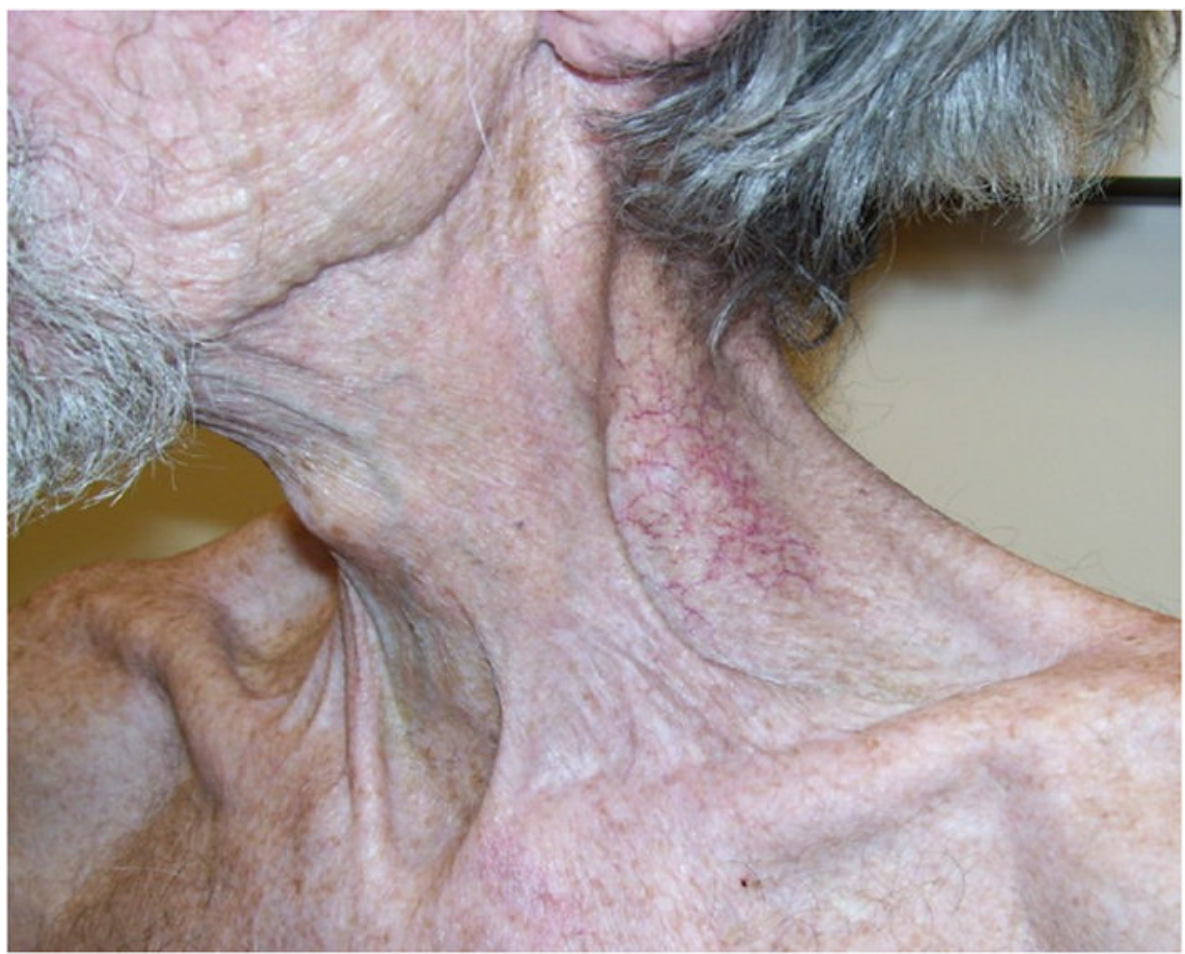

Figure 4.

A 67 year old man with a history of radiation treatment for tonsillar cancer with evidence of neck fibrosis and telangiectasias. 


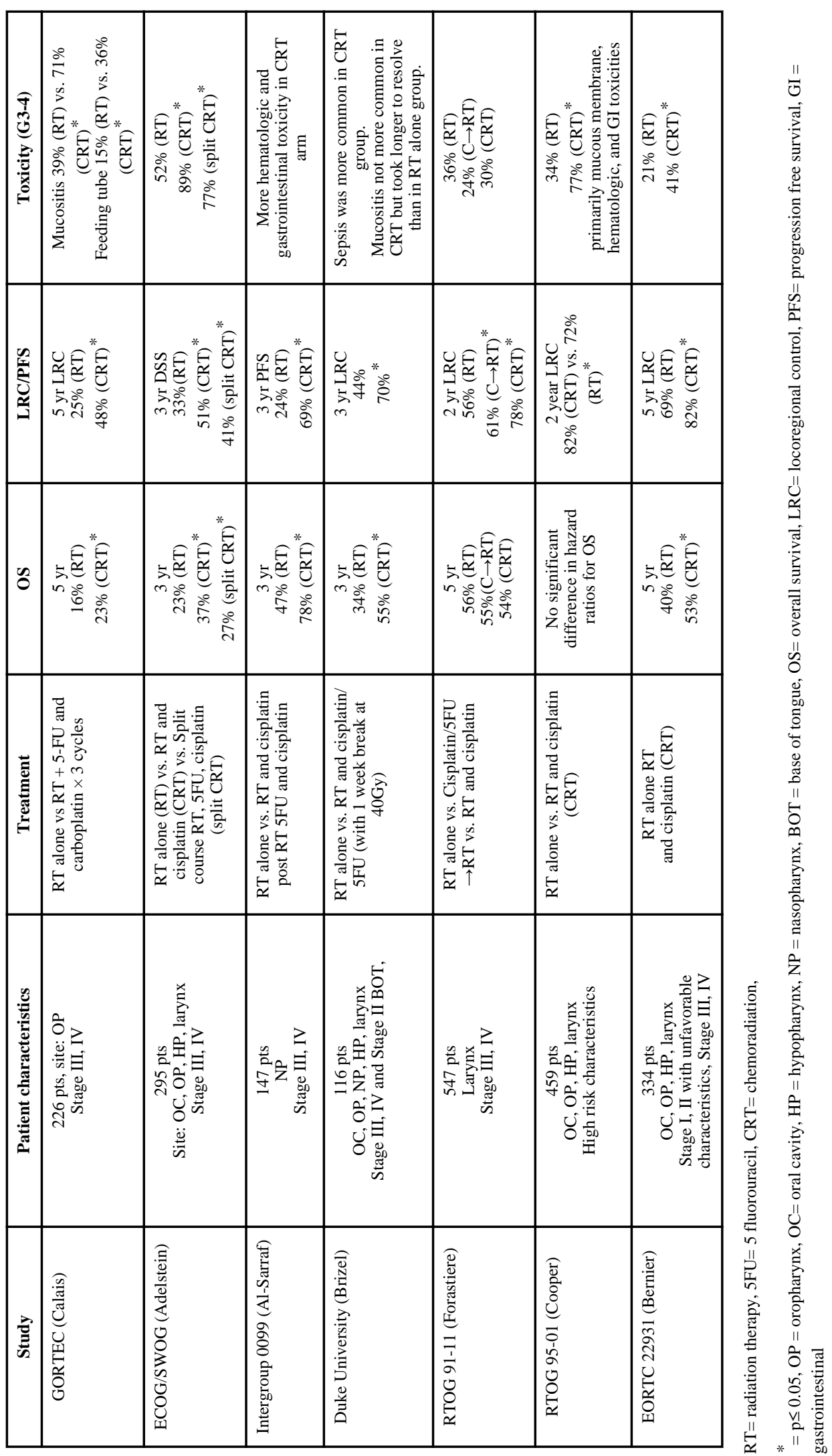




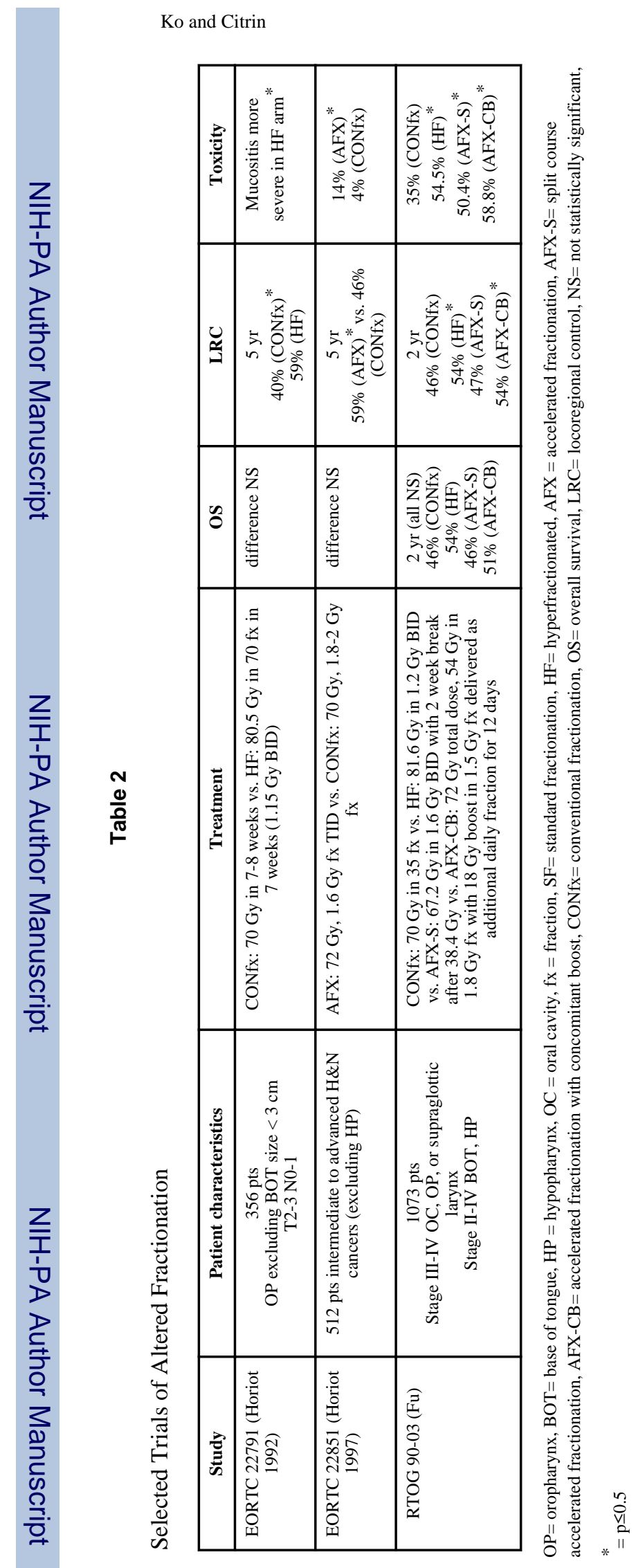

Oral Dis. Author manuscript; available in PMC 2010 March 1. 


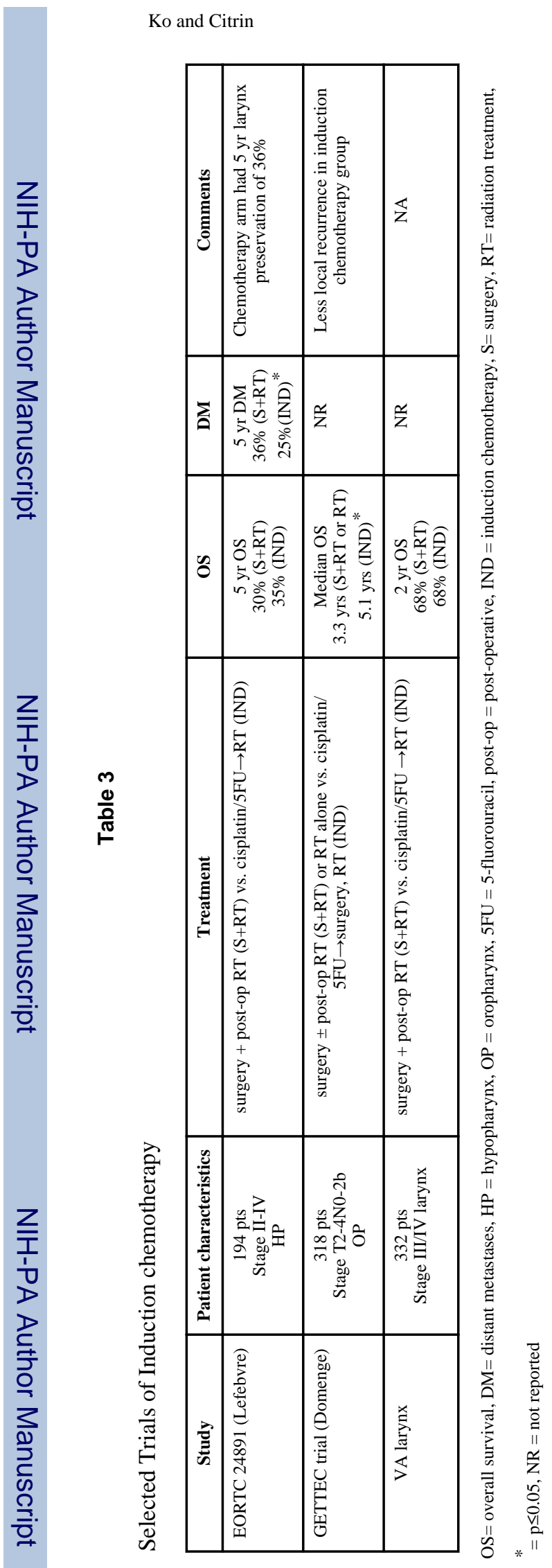

Oral Dis. Author manuscript; available in PMC 2010 March 1. 